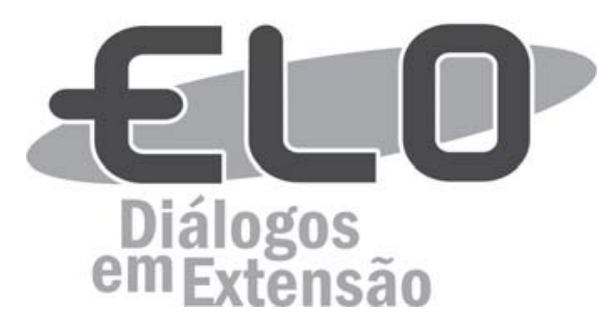

\title{
Aproximando produção e consumo: a experiência do projeto de extensão "Quintal Solidário"
}

Bianca Aparecida Lima Costa ${ }^{1}$ Carla Cristina Balbino dos Santos ${ }^{2}$ e Silvia Eloiza Priore ${ }^{3}$

Resumo: O presente trabalho visa apresentar a experiência das ações do projeto de extensão "Quintal Solidário: Feira de Economia Solidária e Agricultura Familiar". O Quintal Solidário foi criado por meio da parceria entre a Seção Sindical dos Docentes da Universidade Federal de Viçosa e o programa de extensão Incubadora Tecnológica de Cooperativas Populares da Universidade Federal de Viçosa. Seu principal objetivo é valorizar e promover a agroecologia por intermédio da economia solidária e agricultura familiar para integração entre produtores(as) e consumidores(as), fortalecendo relações solidárias, o consumo consciente, produção sustentável e a segurança alimentar e nutricional. Os principais resultados alcançados são a constituição de um mercado ou espaço de comercialização diferenciado, a geração de renda, assessoria técnica e formação, interação social, articulação entre o ensino, pesquisa e extensão e o fortalecimento do comércio justo e consumo solidário.

Palavras-chave: Economia Solidária. Agricultura Familiar. Agroecologia.

Área Temática: Agroecologia.

Solidarity relations, sustainable production and conscious consumption: Quintal Solidário experience - Fair of Solidarity Economy and Family Agriculture

Abstract: This paper aims to present the experience of the activities of the extension project "Quintal Solidário: Fair of Solidary Economy and Family Agriculture". The Quintal Solidário was created through the partnership between the Trade Union Section of the Teachers of the Federal University of Viçosa and the extension program Incubator Technological of Popular Cooperatives of the Federal University of Viçosa. Its main objective is to value and promote agroecology through solidarity economy and family agriculture for integration between producers and consumers, strengthening solidary relationships, conscious consumption and sustainable production. The main results achieved are the creation of a differentiated market or marketing space, the generation of income, technical advice and training, social interaction, articulation between teaching, research and extension and the strengthening of fair trade and conscious consumption.

Keywords: Solidary Economy. Family Agriculture. Agroecology.

Thematic area: Agroecology.

Relacionessolidarias, producciónsostenible y consumoconsciente: experiencia del Quintal Solidario - Feria de EconomiaSolidaria y Agricultura Familiar

Resumen: El presente trabajo pretende presentar la experiencia de lasaccionesdelproyecto de extensión "Quintal Solidario: Feria de Economía Solidaria y Agricultura Familiar". El Quintal Solidariofuecreado

\footnotetext{
Universidade Federal de Viçosa. Professora do Departamento de Economia Rural. Coordenadora do programa de Extensão da ITCP-UFV. E-mail: bianca.lima@ufv.br. Endereço: Rua Tabelião Machado, nº98, apt 301, Bairro: Lourdes - Viçosa/MG. Tel: (31) 3899-1317.

${ }^{2}$ Bacharel em Cooperativismo.

${ }^{3}$ Universidade Federal de Viçosa. Professora do Departamento de Nutrição e Saúde. Coordenadora do Projeto de ExtensãoFeira de Economia Solidária e Agricultura Familiar - Quintal Solidário (PRJ-088/2017).
} 
a través de laasociación entre laSección Sindical de los Docentes de laUniversidad Federal de Viçosa y el programa de extensión Incubadora Tecnológica de Cooperativas Populares de laUniversidad Federal de Viçosa. Su principal objetivo es valorizar y promover laagroecología a través de laeconomía solidaria y la agricultura familiar para laintegración entre productores y consumidores, fortaleciendolas relaciones solidarias, el consumo consciente, laproducciónsostenible y laseguridad alimentaria y nutricional. Los principales resultados alcanzadossonlaconstitución de un mercado o espacio de comercialización diferenciada, lageneración de ingresos, asesoría técnica y formación, interacción social, articulación entre laenseñanza, lainvestigación y laextensión y elfortalecimientodel comercio justo y el consumo consciente.

Palabras clave: Economía Solidaria. Agricultura Familiar. Agroecología.

Área temática: Agroecología.

\section{Introdução}

As feiras são espaços que promovem o acesso aos mercados e a aproximação de produtores(as) e consumidores(as), especialmente em níveis locais. Essas estratégias promovem circuitos curtos de comercialização que contribuem para o fortalecimento da agricultura familiar, a economia solidária, e agroecologia. Essas experiências têm se ampliado em diferentes espaços e potencializam não só a organização econômica, como também a segurança alimentar e nutricional, o comércio justo e o consumo solidário.

Ações dessa natureza foram criadas em consonância com variadas políticas públicas de incentivo à agricultura familiar e à alimentação segura, além da geração de trabalho e renda a partir da economia solidária, recebendo o respaldo e apoio do Governo Federal, principalmente no período de 2003 a 2016, e de instâncias públicas estaduais e municipais. Várias universidades do Brasil, cumprindo seu papel fundamental de contribuir para o desenvolvimento econômico e social brasileiro, têm realizado feiras com essas temáticas em suas sedes. Esses espaços constituem-se como laboratórios sociais que integram ensino, pesquisa e extensão e contribuem para uma sociedade mais justa e sustentável. As experiências, em geral, apoiam-se nos parâmetros do decreto $n^{\circ} 7.358$ de 17 de novembro de 2010 que estabelece o Sistema Nacional de Comércio Justo e Solidário que se trata de uma prática comercial diferenciada pautada nos valores de justiça social e de solidariedade realizada pelos empreendimentos econômicos solidários.

Nesse contexto, a Seção Sindical dos Docentes da Universidade Federal de Viçosa (ASPUV) e o programa de extensão Incubadora Tecnológica de Cooperativas Populares da Universidade Federal de Viçosa (ITCP-UFV) ${ }^{4}$ iniciaram uma parceria em junho de 2016 para organização de um espaço que pudesse potencializar iniciativas locais solidárias por meio do "Quintal Solidário: Feira de Economia Solidária e Agricultura Familiar" realizada na sede da ASPUV. Trata-se de um projeto de extensão devidamente registrado no sistema RAEX com o número: PRJ-088/ 2017.

Dessa forma, o principal objetivo do Quintal Solidário é valorizar e promover a agroecologia por meio da economia solidária e agricultura familiar para integração entre produtores(as) e consumidores(as), fortalecendo relações solidárias, o consumo consciente e a produção sustentável. Além de apoiar a coleta seletiva e contribuir com espaços de formação para os expositores(as) com o intuito de melhorar a qualidade dos seus produtos e acessar novos mercados.

\section{Referencial teórico: apontamentos sobre comércio justo e consumo solidário}

A economia solidária compreende um conjunto de iniciativas baseadas na autogestão e na organização coletiva de atividades econômicas, que podem ser de produção, distribuição, circulação e consumo.De acordo com Coraggio (2017), essas experiências estão centradas na reprodução e desenvolvimento da vida humana e da natureza, orientadas por princípios éticos.

A economia solidária pode representar o início de transformações locais, que mudam o relacionamento entre os cooperadores(as) e destes(as) com a família, vizinhos(as), autoridades públicas, 
religiosas, intelectuais, promovendo mudanças em níveis individual e social. Para tanto, é necessário garantir certas estruturas para sua sustentação como financiamento, redes de comercialização, assessoria científica e técnica, formação contínua dos trabalhadores(as), normativa legal adequada, entre outros (SINGER, 2007, 2003).

No contexto da economia solidária, o comércio justo e solidário envolve a produção e o consumo segundo valores de sustentabilidade e justiça. Trata-se de um sistema de articulação entre produtores(as), comerciantes(as) e consumidores(as) a partir de relações de confiança, transparência e proximidade. Segundo Cotera e Ortiz (2009), osprocessos alternativos de comercialização se iniciaram há mais de 50 anos, especialmente a partir das articulações de organizações não-governamentais dos países do Norte com grupos de produtores de países do Sul, buscando reverter as injustiças das trocas realizadas no comércio internacional. Nesse sentido, o comércio justo engloba a perspectiva de um intercâmbio de produção-distribuição-consumo visando um desenvolvimento solidário e sustentável.

O que inicialmente poderia centrar-se em relações praticadas entre países, ampliou-se fazendo surgir experiências instituídas que também revitalizaram mercados locais em países do Sul. Trata-se de iniciativas que possibilitam a proximidade e solidariedade entre quem produz e quem consome, buscando estabelecer a relação mais direta possível, reduzindo a intervenção entre especuladores e intermediários convencionais, praticando relações que garantam o preço justo (COTERA e ORTIZ, 2009).

O movimento do comércio justo, de acordo com Cotera e Ortiz (2009), é estabelecido em consonância com diferentes contextos socioeconômicos, políticos, culturais e ambientais, mas no geral envolve diferentes atores que são fundamentais para as trocas econômicas mais justas. Essas experiências têm vários objetivos, como fazer evoluir práticas comerciais em direção à sustentabilidade e à incorporação dos custos sociais e ambientais, incidindo sobre a conscientização das pessoas. É importante destacar que esse movimento se vincula com a proposição também do consumo ético e solidário.

No Brasil, as iniciativas e debates em torno dessa temática ampliaram-se a partir de 2000 por meio de diferentes movimentos. Nesse contexto, as feiras promovem o acesso aos mercados e a aproximação de produtores(as) e consumidores(as), especialmente em níveis locais. Essas estratégias promovem circuitos curtos de comercialização que contribuem para o fortalecimento da agricultura familiar, a economia solidária e agroecologia. Essas experiências têm se ampliado em diferentes espaços e potencializam não só a organização econômica, como também a segurança alimentar e nutricional, assim como o comércio justo e o consumo solidário, conforme relato de experiência que se segue.

\section{Metodologia do Projeto de Extensão "Quintal Solidário"}

Para organização da feira, foi constituída uma comissão com integrantes de entidades parceiras afetas às temáticas em questão que contribuíram para elaboração das diretrizes e seleção dos(as) expositores(as). As organizações envolvidas no apoio ao Quintal são: Empresa de Assistência Técnica e Extensão Rural (EMATER), Serviço de Vigilância Sanitária de Viçosa, Associação de Artesãos e produtores de Alimentos Caseiros da Região de Viçosa (ADAPAC), Centro de Tecnologias Alternativas da Zona da Mata (CTA-ZM), Rede Raízes da Mata, Projeto de Extensão da Feira Agroecológica e Cultural da Violeira da Universidade Federal de Viçosa e Departamento de Nutrição e Saúde.

A seleção dos expositores(as) ocorreu por meio do Edital público lançado em setembro de 2016 sob o título "EDITAL DE INSCRIÇÃO Nº 001/2016 PARA SELEÇÃO DE EXPOSITORES(AS) PARA O QUINTAL SOLIDÁRIO - FEIRA DE ECONOMIA SOLIDÁRIA E AGRICULTURA FAMILIAR". Podiam se inscrever no chamamento 1) Empreendimentos Econômicos Solidários (grupos, associações, cooperativas) e 2) Agricultores(as) Familiares que buscavam espaço de comercialização e divulgação de seus produtos e serviços. Conforme consta no documento, a partir de normativas do Governo Federal, os Empreendimentos Econômicos Solidários caracterizam-se por serem grupos associativos e suprafamiliares que realizam atividades econômicas permanentes, cujos participantes são trabalhadores do meio urbano ou rural e exerçam democraticamente a gestão das atividades e a alocação dos resultados e os(as) agricultores(as) familiares são aqueles(as) que praticam atividades no meio rural, atendendo, simultaneamente, aos seguintes requisitos: não detenha, a qualquer título, área maior do que 4 (quatro) módulos fiscais; utilize predominantemente mão-de-obra da própria família nas atividades econômicas do seu estabelecimento ou empreendimento; tenha renda familiar predominantemente originada de atividades econômicas vinculadas ao próprio estabelecimento ou empreendimento; dirija seu estabelecimento ou empreendimento com sua família. 
Para ter direito à inscrição, os(as) solicitantes deveriam apresentar os seguintes documentos de acordo com as especificidades de suas organizações: I- Declaração de Aptidão ao Pronaf (DAP) para os agricultores(as) familiares ou Cadastro Nacional de Empreendimentos Econômicos Solidários (CADSOL) para os empreendimentos econômicos solidários. Esses documentos são utilizados para acesso às políticas públicas específicas e são normatizados por lei. Portanto, ao vincular a feira aos instrumentos de políticas públicas de beneficiários prioritários, estamos assumindo que o Quintal, para além de um caráter de experimentação, constitui-se também como um processo de inclusão produtiva. Aspecto que compõe os pilares das Universidades Públicas Brasileiras.As inscrições foram analisadas pela comissão de seleção da Feira composta por: ASPUV, ITCP-UFV, EMATER, CTA-ZM, Serviço de Vigilância Sanitária de Viçosa e Projeto de Extensão da Feira Agroecológica.

Além da seleção pública, a Feira detém Regimento Interno visando o cumprimento de regras que assegurem seus princípios. A Comissão organizadora da feira se reúne toda semana e uma vez por mês são realizadas reuniões de avaliação e planejamento com os(as) expositores(as). As discussões e encaminhamentos gerados nessas reuniões contribuíram para o fortalecimento da autogestão do grupo, para o convívio e integração entre os(as) participantes(as). Trata-se de uma oportunidade de interação com representantes de diversos grupos da economia solidária, agricultores e agricultoras familiares, estudantes, professores e visitantes da feira.

A feira iniciou suas atividades em setembro de 2016 em edições, inicialmente, quinzenais e, a partir de 08 de março de 2017, passaram a ser semanais, reunindo um público consumidor que varia entre 300 a 600 pessoas por feira.

Atualmente, a feira envolve 96 pessoas direta e indiretamente. O perfil das iniciativas envolvidas é variado, englobando movimentos sociais, redes de prosumidores, pacientes da saúde mental e participantes de projetos de inclusão social. No total, são 35 barracas/bancadas divididas em três setores: a)Artesanato (14); Alimentos minimamente processados(12) e Hortifruti (09). Com a participação direta de 35 expositores(as) dos municípios de Viçosa, Ervália, Teixeiras e Coimbra.

Dentre os três setores mencionados anteriormente, os principais produtos ofertados são artigos para cozinha, cama e banho, bolsas, e artigos para decoração, bonecas de pano e de crochê, tapetes, bolos, roscas, queijos, manteigas, frutas desidratadas, sucos, pães, salgados vegetarianos e veganos, doces, compotas, pó de café, cogumelos, frutas, legumes e verduras.

Por categoria, o Quintal solidário conta atualmente com a participação de 7 empreendimentos econômicos solidários: 1) Associação de Artesãos e produtores de Alimentos Caseiros da Região de Viçosa; 2) Arte em Tecidos Patchwork; 3) As Samaritacas; 4) Rede Raízes da Mata; 5) SEMEARTGrupo da Produção Solidária; 6) Associação dos Produtores de Agroartesanatos de Viçosa e 7) Coletivo de Costura do Centro Tecnológico de Alternativas. Além disso, são envolvidas iniciativas de grupos inseridos na Feira Agroecológica da Violeira, 9 representantes da Agricultura Familiar.

Além da comercialização a feira pretende ser um espaço de convivência e integração social, abrindo as portas da Universidade Federal de Viçosa para comunidade de Viçosa por meio de atrações culturais, espaço para crianças e ofertas de oficinas.

A programação cultural da Feira, por exemplo, busca a valorização das atrações locais e desde o início do Quintal já foram realizadas diferentes atividades como apresentações musicais, oficinas de dança, cirandas, coral e capoeira. Trata-se do incentivo à produção cultural, fortalecendo a economia criativa local em consonância com as atividades propostas pela ITCP-UFV no Programa Mais Cultura "UFV ArtCulAção", executado pela Universidade com apoio do Governo Federal.

O espaço infantil da feira oferece atividades lúdicas por meio dos seguintes projetos de extensão do curso de Educação Infantil: "Contação de Histórias: promovendo a imaginação e o lúdico", "Meio ambiente e ludicidade: construindo conceitos por meio da experimentação", "Resgatando a cultura lúdica na infância" e "MusiC-Art: entre vozes e ecos da cultura musical". Nesse espaço, as crianças também participam de atividades relacionadas às diferentes temáticas, como, por exemplo, reciclagem e meio ambiente.

Periodicamente, são oferecidas gratuitamente oficinas com temas diversos ministradas por representantes dos empreendimentos que participam da feira e estudantes ou professores que integram projetos de extensão da UFV. Entre os temas já abordados podemos destacar: compostagem, Microorganismos Eficientes (E.M), hortas verticais, manipulação e conservação de alimentos, preparação de sucos verdes e diversas técnicas de artesanatos confeccionados a partir de materiais recicláveis. 
Com o enfoque ambiental, destaca-se também a participação do Projeto Interação Responsabilidade e Meio Ambiente, na implementação da Coleta Seletiva no Quintal. Dentre as atividades realizadas para maior conscientização do público, está exposição de fotos e formação sobre a temática com os expositores(as). A feira também se tornou um ponto de recolhimento de óleo usado, inicialmente através da parceria com uma empresa local e atualmente em parceria com empreendimentos econômicos solidários do segmento de reciclagem. Para cada 2 litros entregues, o cliente recebe uma moeda social para ser gasta no Quintal. Reforça-se, assim, a importância do tema ambiental e da sustentabilidade na feira.

\section{Resultados e discussões}

Um primeiro ponto importante a ser destacado relaciona-se com a constituição de um mercado ou espaço de comercialização diferenciado para agricultores(as) familiares com práticas de manejo sustentáveis, priorizando-se a transição agroecológica. Por meio das organizações parceiras ocorrem o acompanhamento e apoioa esses(as)agricultores(as) e o trabalho para o avanço nessa questão. Um dos objetivos do Quintal Solidário é fomentar esse debate e fortalecer essas iniciativas e sua transição.

A geração de renda para os(as) expositores(as) também é um dos resultados que pode ser mencionado. A partir de avaliações com os participantes, é possível perceber que a feira representa um espaço em que há um retorno financeiro tanto para agricultores(as) familiares quanto para os empreendimentos econômicos solidários.

O projeto também gerou demandas para assessoria técnica e formação e foramrealizadas oficinas sobre boas práticas de manipulação de alimentos, o que proporcionou a troca de experiências e saberes entre os participantes, agregando e compartilhando conhecimentos. Essa formação terá continuidade e outros temas também estão sendo trabalhados como a rotulagem. Objetiva-se, nesse sentido, melhorar e adequar esses produtos para segurança do consumidor e também para conquista de outros mercados.

No mesmo contexto, através das oficinas de artesanatos, os(as) expositores(as) e público em geral tiveram a oportunidade de aprender novas técnicas ou aprimorar técnicas de produção já conhecidas. Com isso, além de aprender a confeccionar novos produtos, estes podem ser comercializados, proporcionando mais uma fonte de ocupação e geração de renda.

Outro aspecto positivo relaciona-se com a articulação e convergência de temas que estão sendo tratados nas feiras. Há diferentes empreendimentos e participantes que consideram a feira não só como um espaço de comercialização como um espaço de interação social. Pode-se destacar, por exemplo, as experiências dos grupos de produção solidária da saúde mental, de movimentos sociais e artesãs.

O Quintal Solidário também tem sido um espaço de articulação de diferentes projetos transformando-se em um "laboratório social" de ensino, pesquisa e extensão. A partir dessa experiência, ações de extensão promovem suas atividades durante a feira. Exemplos disso são as atividades lúdicas para crianças, a conscientização para a coleta seletiva e as oficinas com diferentes temáticas. Várias pesquisas já estão sendo realizadas a partir dessa experiência, assim como a interação com cursos como Economia Doméstica, Educação Infantil, Nutrição e Cooperativismo. A feira já foi visitada por outras instituições como Instituto Federal de Rio Pomba e Universidade Federal de Ouro Preto, visando a replicação da experiência em suas sedes. Além disso, diversos representantes de órgãos públicos e de organizações não governamentais já estiveram no espaço em busca de informações. Ressaltam-se ainda os estudantes intercambistas e os projetos de cooperação internacional da UFV que visitaram e acompanharam as atividades do Quintal.

E, por fim, a feira tem se destacado como movimento de promoção da produção e comercialização de produtos da agroecologia e da economia solidária. Nesse sentido, há a incidência na qualidade e visibilidade desses trabalhos, fortalecendo o comércio justo e o consumo solidário.

\section{Considerações finais}

Compreendemos que a iniciativa, portanto, está em consonância com os pilares da Universidade Pública brasileira e tem promovido o desenvolvimento de tecnologias e inovações sociais a partir de uma construção coletiva com diversos parceiros locais. Trata-se de um espaço rico que congrega diferentes temáticas, integrando ensino, pesquisa e extensão. 


\section{Fontes de financiamento}

Os recursos iniciais para a execução do Quintal Solidário foram obtidos por meio da ASPUV e contou também com a Fundação de Amparo à Pesquisa de Minas Gerais no período de agosto/2016 a maio/2017 com o custeio da bolsa de dois técnicos para a realização de atividades previstas no projeto "O papel do movimento social na construção de políticas públicas locais: a experiência do fórum regional de economia popular solidária na Zona da Mata Mineira".

Na área cultural, recebe também recursos do Programa Mais Cultura "UFV ArtCulAção", desde 2017. Do final de 2017 a dezembro de 2018, passou a receber apoio do projeto "RESSOA NA MATA: Redes de Economia Solidária e Agroecologia na Zona da Mata de Minas Gerais", financiado pelo CNPQ e SENAES (processo $n^{\circ} 441897 / 2017$ ). O projeto conta também com patrocínio desde 2019 do SICOOB UFVCredi.

Além do apoio financeiro, o Quintal solidário conta com o apoio do Programa de Extensão Universitário ITCP-UFV envolvendo bolsistas e voluntários na coordenação e execução de suas ações, assim como outros projetos de extensão e o Departamento de Nutrição e Saúde.

\section{Agradecimentos}

Agradecemos aos expositores e expositoras do Quintal Solidário, à ASPUV, à ITCP aos projetos de extensão da do curso de Educação Infantil: "Contação de Histórias: promovendo a imaginação e o lúdico", "Meio ambiente e ludicidade: construindo conceitos por meio da experimentação", "Resgatando a cultura lúdica na infância" e "MusiC-Art: entre vozes e ecos da cultura musical" e Projeto Interação - Responsabilidade e Meio Ambiente. Aos nossos parceiros: Empresa de Assistência Técnica e Extensão Rural (EMATER), Serviço de Vigilância Sanitária de Viçosa, Associação de Artesãos e produtores de Alimentos Caseiros da Região de Viçosa (ADAPAC), Centro de Tecnologias Alternativas da Zona da Mata (CTA-ZM), Rede Raízes da Mata, Projeto de Extensão da Feira Agroecológica, Cultural da Violeira, Departamento de Nutrição e Saúde (UFV), SICOOB UFVCredi e Fundação Arthur Bernardes.Agradecemos também o apoio da Pró-Reitoria de Extensão e Cultura, especialmente a Divisão de Eventos. Aos músicos locais que fazem apresentações no espaço cultural da feira, a todos(as) os(as) professores(as), alunos e voluntários(as) envolvidos(as).

\section{Referências Bibliográficas}

COTERA, A., ORTIZ, H. Comércio Justo. In: CATTANI, Antônio David; LAVILLE, Jean-Louis; HESPANHA, Pedro (Orgs.) Dicionário Internacional da Outra economia. Coimbra: Altamira, 2009.p. 60-67

CORAGGIO, José Luís. Economia Social e solidária: os alcances do projeto e da política. In: SOUZA, A.R,; ZANIN,; M. (Orgs.). A Economia Solidária e os desafios globais do trabalho. São Carlos: Edufscar, 2017. pp - 31-46.

SINGER, Paul. Economia solidária: um modo de produção e distribuição. In: SINGER, Paul; SOUZA, André Ricardo de. (orgs.) A economia solidária no Brasil: a autogestão como resposta ao desemprego. São Paulo: Contexto, 2003. p.11-30.

SINGER, Paul. In: Economía solidaria. Um modo de produccíon y distribuición. CORAGGIO, José Luis. La economia social desde la periferia: contribuicioneslatinoamericanas. Buenos Aires: Altamira, 2007. p. 59-78.

Data de submissão: 23/9/2018 Data de aceite: 3/5/2019.

\footnotetext{
${ }^{4}$ A Incubadora Tecnológica de Cooperativas Populares da Universidade Federal de Viçosa - ITCP-UFV é um programa de extensão, interdisciplinar, fundado em 27 de outubro de 2003. Institucionalmente, a iniciativa é vinculada diretamente à Pró-Reitoria de Extensão e Cultura da UFV. Desde sua criação, a ITCP-UFV vem assessorando grupos populares que desenvolvem diversas atividades econômicas, no âmbito da agricultura familiar, do artesanato, da reciclagem popular, alimentação, prestação de serviços, entre outras.
} 